Dr. Amanda Cahill-Ripley

Lecturer in Law | Lancaster University Law School

Bowland North | Bailrigg | Lancaster | LA1 4YL

Tel: 01524594930

a.cahill@lancaster.ac.uk

\title{
'Innovative methods of assessment in Law: The value of open book exams as a catalyst for improving teaching and learning in the Law School’
}

\begin{abstract}
The question of whether open-book exams (OBE) are preferable to closed book examinations (CBE) is not a new one. However, little has been written on the question of the use of OBE in the discipline of Law or as a means of promoting more effective teaching and learning. This article will examine the arguments for and against the utilisation of OBE as oppose to CBE for students of Law at university level. Utilising secondary data, as well as a primary small scale empirical study the author explores student views of OBE and CBE and their significance for teaching and learning in Law. It is suggested that the issue may not be simply a question of choice of assessment methods and their value but rather involves examining and evaluating approaches to teaching, learning and curriculum design. In conclusion it is argued that there are several factors which need to be taken into account when deciding what form of assessment is the most appropriate for these students but that the key requirement is that the course design and teaching, learning and assessment methods are aligned and considered as a whole, matching learning outcomes to teaching and learning activities and to the form of assessment chosen. Only within this context can OBE promote more effective learning.
\end{abstract}

213 words 


\section{Key words noted in bold}

\section{Innovative methods of assessment in Law: The value of open book exams as a catalyst for improving teaching and learning in the Law School}

\section{Introduction}

The question of whether open-book exams (OBE) are preferable to closed book examinations (CBE) is not a new one. ${ }^{1}$ However, much of the previous literature has focussed on smallscale empirical studies in a particular discipline ${ }^{2}$ rather than examining the impact of OBE if implemented widely 'as a means of promoting more effective learning at higher cognitive levels. ${ }^{3}$ Moreover, little has been written on the question of the use of OBE in the discipline of Law. ${ }^{4}$ This article will examine the arguments for and against the utilisation of OBE as oppose to CBE for students of Law at university level. It is suggested that the issue may not be simply a question of choice of assessment methods and their value but rather involves examining and evaluating approaches to teaching, learning and curriculum design. In conclusion it is argued that there are several factors which need to be taken into account when deciding what form of assessment is the most appropriate for these students but that the key requirement is that the course design and teaching, learning and assessment methods are

\footnotetext{
${ }^{1}$ For example, Stalnaker, J.M., \& Stalnaker, R.C, 'Open-book examinations: Results', With the Technicians. 5, 1935, pp.214-216; Tussing, L, 'A consideration of the open book examination', Educational and Psychological Measurement, 11, 1951, pp.597-602; Anderson, L.W. \& Sosniak, L.A, Bloom's taxonomy: A forty-year retrospective, Chicago: University of Chicago Press, 1994.

${ }^{2}$ Mostly in the sciences or engineering; For example see Baillie. C \& Toohey. S, "The "power test": Its impact on student learning in a material science course for engineering students', Assessment and Evaluation in Higher Education, 22 (1), 1997, pp.33-48; Philips. G, 'Using open book tests to encourage textbook reading in college’, Journal of Reading, 38 (6), 1995, pp.484-9.

${ }^{3}$ Eilertsen.T.V and Valdermo.O, 'Open-Book Assessment: A Contribution to Improved Learning?' in Studies in Educational Evaluation, 26, 2000, pp.91-103 at p.92.

${ }^{4}$ With the notable exception of the excellent article by Maharg.P, 'The culture of mnemosyne: Open-book assessment and the theory and practice of legal education', International Journal of the Legal Profession, 6:2, 1999, pp.219-239.
} 
aligned and considered as a whole, matching learning outcomes to teaching and learning activities and to the form of assessment chosen. If this requirement is fulfilled then both OBE and CBE (or a mixture of both) can act as effective assessment. However, the use of OBE can act as a catalyst to 'promote study and teaching methods that improve understanding' and encourages thinking at higher cognitive levels. ${ }^{5}$

\section{Definition of OBE}

'In its most basic form, open-book assessment (OB) refers to students' use of textbooks, notes, journals, and reference materials while taking tests. ${ }^{6}$ The OBE has been proposed as an alternative and more effective method of assessment to the closed book examination which is 'an established procedure in higher education in the sense that is both widely and frequently applies...[it] requires students to answer test questions based on their ability to use the knowledge they can recall'. ${ }^{7}$ Student achievement is graded against 'the ability to memorise facts and what others have thought and said..." ${ }^{8}$ In contrast, OBE have been associated with evaluation of high level cognitive skills such as 'conceptualising, problemsolving and reasoning.' 9 The purpose of an open book examination therefore is 'to promote higher - order thinking by having students draw upon information from various sources and

\footnotetext{
${ }^{5}$ Eilertsen.T.V and Valdermo.O, 2000, p.91.

${ }^{6}$ Ibid. See also Theophilides. C and Koutselini. M, 'Study Behaviour in the Closed-Book and the Open-Book Examination: A Comparative Analysis' in Educational Research and Evaluation: An International Journal on Theory and Practice, 6:4, 2000, pp.379-393, at p.379.

${ }^{7}$ Theophilides. C and Koutselini.M, 2000, p.379.

8 Koutselini Ioannidou. M, 'Testing and Life-Long Learning: Open-Book and Closed-Book Examination in a University Course', in Studies in Educational Evaluation, 23:2, 1997, pp.131-139 at p.131.

${ }^{9}$ Ibid., p.131. See also Evangelia Karagiannopoulou \& Fotios S. Milienos, 'Exploring the relationship between experienced students' preference for open- and closed-book examinations, approaches to learning and achievement', Educational Research and Evaluation: An International Journal on Theory and Practice, 19:4, 2013, pp.271-296 at p.274.
} 
synthesise their answers, ${ }^{10}$ which in turn improves understanding. ${ }^{11}$ This also allows the lecturer to assess the student's skills concerning identifying and retrieving appropriate information, applying these sources to the particular case/context and critically analysing that information.

\section{Pros and Cons of OBE}

Benefits of open-book examinations include the reduction of rote learning and memorisation of facts ${ }^{12}$ leading to lasting learning outcomes. ${ }^{13}$ Students also feel more optimistic about their performance in an open book exam than a closed book (traditional) examination thus reducing exam stress and anxiety. ${ }^{14}$ In turn this allows for a more thoughtful approach to the questions and calmer measured pre-exam preparation. Conversely however, overconfidence regarding the exam can also lead to a lack of preparation as students underestimate the research and studying that is required, ${ }^{15}$ believing an OBE to be easier. ${ }^{16}$ A further disadvantage of OBE when compared to CBE is the claim that there is less time for the students to formulate and write answers during the exam as much time is spent locating information and reading ${ }^{17}$ although it is argued that this can be countered by having a longer exam period and by good preparation of materials.

\footnotetext{
10 Theophilides. C and Koutselini.M, 2000, p.382.

${ }^{11}$ Eilertsen.T.V and Valdermo.O, 2000, p.91.

12 Ibid.

13 Theophilides. C and Koutselini.M, 2000, p.380.

${ }^{14}$ Ibid., pp.380; 388; 390-391. Evangelia Karagiannopoulou \& Fotios S. Milienos, 2013, p.274.

${ }^{15}$ Ibid.

${ }^{16}$ Koutselini Ioannidou, 1997, p.136.

${ }^{17}$ Theophilides. C and Koutselini.M, 2000, p.380.
} 
In terms of exam preparation students prepare for closed-book exams by 'cramming' or memorising information, particularly facts, immediately before the examination at the end of the term or semester. ${ }^{18}$ This results in overwhelmingly in surface or shallow learning, usually based upon key texts only. ${ }^{19}$ On the contrary preparation for open book examinations require the student to practice study skills such as note taking and identifying and retrieving relevant information from materials including going beyond set textbooks, encourages students to look for the links across the curriculum and to apply higher-order thinking; critical analysis, evaluation, synthesis. ${ }^{20}$ Preparing for an open book exam encourages deep knowledge through developing vertical and horizontal interconnections ${ }^{21}$, meaning that students make the links between previous learning in the same course and connections with other subjects and topics e.g. other courses.

\section{OBE as a learning experience}

Another argument for the use of OBE is that the examination itself becomes a learning process - an exercise in utilising study skills and thinking skills and through knowledge transfer. $^{22}$ However, in order for students to feel confident with using the OBE as an 'arena for learning, ${ }^{23}$ and to benefit from OBE in this way the students must have confidence in the marking criteria. i.e. that they can utilise the OBE in such a way as to not lose marks if they treat it as a learning exercise rather than an exercise in regurgitating facts. The author is not aware of any material examining marking criteria in relation to OBE. However, it is

\footnotetext{
${ }^{18}$ Theophilides. C and Koutselini.M, 2000, p.383; Donnelly.L, 'A Modest Proposal: The Case for the Open-Book Law Exams', European Journal of Legal Education, 2(2), 2005, pp.105-109 at p.107.

${ }^{19}$ For a definition of surface learning see Edward Phillips, Sandra Clarke, Sarah Crofts \& Angela Laycock, 'Exceeding the boundaries of formulaic assessment: innovation and creativity in the law school', The Law Teacher, 44:3, 2010, pp.334-364 at p.330.

${ }^{20}$ Theophilides. C and Koutselini.M, 2000, p.384.

${ }^{21}$ As defined by Biggs (1995) in Theophilides. C and Koutselini.M, 2000, p.392.

${ }^{22}$ Theophilides. C and Koutselini.M, 2000, p.391.

${ }^{23}$ Eilertsen.T.V and Valdermo.O, 2000, p.101.
} 
enlightening to note the definition of an OBE put forward by Kalish which states 'an [OBE is an] examination during which the student is allowed to make use of materials as his disposal, ...but does not obtain answers either directly or indirectly from students. ${ }^{\text {, }}{ }^{24}$ Thus, herein may lie the perceived problem with OBE in that it is difficult to quantify achievement in an OBE in the way that achievement is measured in CBE. This raises the issue of the educational context in which lecturers must operate. In particular, assessment is subject to administrative constraints; workload issues, professional bodies' demands ${ }^{25}$, University regulations and the preferences of employers. This is particularly marked when dealing with examinations and results. When lecturers do seek to be innovative and change from the orthodoxy of CBE to alternative examinations methods it is fact often administrative issues wish form the basis of opposition, rather than pedagogical opposition. ${ }^{26}$

\section{Curriculum design not just assessment}

It is clear that to move to an OBE from a CBE is not just a question of changing the method of assessment. Rather it requires a change in the way we as lecturers approach the teaching and learning activities of our courses as a whole. This will entail consideration of the learning outcomes and designing the curriculum with the teaching and learning of higher cognitive skills in mind. ${ }^{27}$ As such the course activities need to prepare students for OBE by facilitating

\footnotetext{
${ }^{24}$ Kalish, R.A, 'An experimental evaluation of the open-book examination', Journal of Educational Psychology, 49, 1958, pp.220-240 at p.200.

${ }^{25}$ See forthcoming discussion on pass requirements of the Bar Standards Board and Solicitors Regulation Authority for a Qualifying Law Degree (QLD).

${ }^{26}$ Donnelly.L, 2005, pp.105-109 at p.108.

${ }^{27}$ Koutselini Ioannidou, 1997, p.132.
} 
the acquisition of reasoning and critical thinking, application and synthesis of knowledge for example through use of problem based learning, self-reflection and self-directed learning. ${ }^{28}$

Furthermore, students need to be informed from the outset of the course that the final examination is of open-book type ${ }^{29}$ so that they can collate their notes and information throughout the course. Students should also be made aware of what materials they are allowed to bring in: full OBE allow students free access to any materials. Others implement various limitations such as allowing students to bring in a file of their notes only. Known as 'Open Notebook' this version of the OBE has been shown to promote effective and systematic note taking throughout the duration of a course and encourages more attentive and engaged students. ${ }^{30}$ Consequently this promotes 'deep learning of the course' ${ }^{\text {,31 }}$ and contributes to the students feeling involved in their own learning. ${ }^{32}$ Another contemporary version of the $\mathrm{OBE}$ is the open-book open-web (OBOW) examination. ${ }^{33}$ In this version of the OBE the students are given 'unstructured problems that require the application of relevant skills and knowledge' acquired in their course of study. They complete the task online with access to the internet but must make direct references to materials utilised on the course. ${ }^{34}$

\footnotetext{
${ }^{28}$ It is significant that there is a lack of operational definitions of critical thinking appropriate to the discipline of law. For further examination of what critical thinking entails see Nickolas James, Clair Hughes \& Clare Cappa, 'Conceptualising, developing and assessing critical thinking in law', Teaching in Higher Education, 15:3, 2010, pp.285-297.

${ }^{29}$ Theophilides. C and Koutselini.M, 2000, p.382.

${ }^{30}$ Eilertsen.T.V and Valdermo.O, 2000, p.99. Moreover, if students have access to a free range of materials this has been shown to actually increase student anxiety, rather than relieving anxiety as students believe they have a shortage to time to make use of the materials.

${ }^{31}$ Theophilides. C and Koutselini.M, 2000, p.388.

${ }^{32}$ Maharg.P, 1999, p.231.

${ }^{33}$ Williams. J and Wong. A, 'The efficacy of final examinations: A comparative study of closed-book, invigilated exams and open-book, open-web exams', British Journal of Educational Technology, Vol.40:2, 2009, pp.227-236.

${ }^{34}$ Ibid., p.230.
} 
Williams and Wong also found that OBOW emphasises the importance of learner-directed discovery of knowledge which engages students and thus induces deeper learning. ${ }^{35}$

Additionally, the lecturer is required to consider the nature of the questions necessary for an effective OBE, for example, what degree of complexity is required and which learning outcomes can be assessed. As Eilertsen and Valdermo note, one of the greatest challenges on OBE is developing and writing comprehensive and compatible OBE questions. It requires the lecturer to be an expert in the specific subject in question, but also to think creatively. ${ }^{36}$ In some cases where OBE have not been effective or successful it is often because the teaching and examinations have been designed for $\mathrm{CBE},{ }^{37}$ thus resulting in the students being illprepared for OBE. The questions most-suited to OBE are problem-based questions which encourage application of skills and knowledge and analysis of the problem, rather than 'data dumping' of facts. ${ }^{38}$ Therefore it is not solely the mode of assessment and process of undertaking the OBE that is significant but also the types of questions asked and the learning outcomes that are assessed that are key to improving learning. As such integrated curriculum design is crucial. 'Following Biggs (1999) constructive alignment of pedagogy, curriculum and assessment, [...] a case-based, problem solving approach is integral to an authentic assessment regime. ${ }^{39}$ Therefore, it may be that the question that needs to be addressed is what is the nature of the teaching, learning and learning outcomes and whether they encourage deeper learning rather than simply focussing on the format of the examination itself. However, it is notable that even in institutions where problem-based learning has been

\footnotetext{
${ }^{35}$ Ibid., p.233.

${ }^{36}$ Eilertsen.T.V and Valdermo.O, 2000, p.98.

${ }^{37}$ Koutselini Ioannidou, 1997, p.131.

${ }^{38}$ Williams. J and Wong. A, 2009, p.230.

${ }^{39}$ Ibid., p.229.
} 
adopted as a departmental approach (rather than at the level of individual modules) formal examinations are still a main form of assessment. ${ }^{40}$

In terms of achievement, interestingly, a small scale study at the University of Cyprus found that there was no significant difference in achievement between students who sat a CBE and those who sat an OBE when both exams were designed to test higher order skills and critical thinking. ${ }^{41}$ The study followed 72 students who were divided into two groups to undertake CBE and OBE on the same topics. Both examinations had sections on multiple choice, problem-solving; and essay type questions measuring ability of argumentation. ${ }^{42}$ Those who sat the CBE performed better in the multiple choice section, which involved understanding terminology, but not in the section based on the ability to construct an argument. ${ }^{43}$ However, those who sat the OBE were found to perform less well overall due to the time spent consulting materials which had a negative impact upon their achievement. ${ }^{44}$ The assumption in the study was that those students who spent too much time consulting materials were the weaker students. ${ }^{45}$ As such the format of an OBE only offered these students an advantage if the teaching and learning process preceding the exam developed the cognitive and research skills necessary to prepare them for such an exam. Only then would achievement be improved. ${ }^{46}$ Thus the compatibility between teaching and learning and learning outcomes and the exam (whether closed or open) is evidently a key factor impacting on student achievement. Whilst OBE can have a positive effect on learning (encouraging deeper

\footnotetext{
${ }^{40}$ See for example University of York Law School, http://www.york.ac.uk/law/undergraduate/3-year-

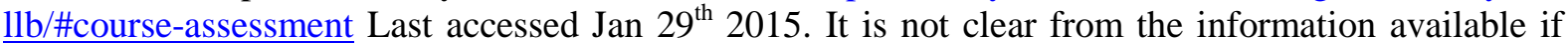
these are CBE.

${ }^{41}$ Koutselini Ioannidou, 1997, p.136.

${ }^{42}$ Ibid., p.134.

${ }^{43}$ Ibid., p.136.

${ }^{44}$ Ibid.

${ }^{45}$ Ibid., p.135.

${ }^{46}$ Ibid.
} 
learning) it is clear that if OBE is to be used effectively the curriculum needs to be designed to include tasks to develop higher order skills in order to prepare students for such examinations; problem solving, reasoning, independent study allowing ownership of learning, group work and research skills: library, online research, note taking, scan reading and retrieving key information are some of the key skills which need to be acquired.

Of course, changes to teaching, learning and assessment are not carried out in isolation and will be constrained by the educational context in which the module is taught. This may be departmental or discipline specific limitations or university specific limitations. These may take the form of educational traditions or custom rather than formal regulations. For example, both students and lecturers hold implicit ideas of what learning entails and what examinations should entail. Thus, 'students' [and lecturers] previous and most implicit learning about learning and about the nature of knowledge [can] collide with the $\mathrm{OB}[\mathrm{E}]$ assumptions and make it difficult to change learning styles. ${ }^{47}$

\section{Particular case of Law}

There is a further question as to whether generalised arguments regarding OBE apply to all subject areas equally or whether the appropriateness of open-book or closed book exams is somewhat subject dependent owing to differences in learning and teaching in specific disciplines. As regards Law, very little research appears to have been conducted on the appropriateness and use of OBE for students undertaking undergraduate degrees in law. ${ }^{48}$ It is also the case that within legal education itself there is some disagreement as to the

\footnotetext{
${ }^{47}$ Eilertsen.T.V and Valdermo.O, 2000, p.95.

${ }^{48}$ Notable exceptions have been referred to in the text. However most articles to date are based in US postgraduate Law Schools with a practitioner emphasis.
} 
appropriate curriculum and educational aims for such courses. i.e. whether they should be more practice focused or whether they should be viewed as purely academic courses on their own merits or a mixture of the two. Depending on the view taken, the appropriateness of OBE as a form of assessment may be questioned.

Interestingly contrary to popular myth amongst staff and students the professional bodies governing legal education and training in England and Wales do not specify or prescribe methods of assessment to be used in the academic stage of legal training, .i.e. a qualifying law degree (QLD). The Academic Stage Handbook states categorically that 'Teaching and learning methodologies and strategies are not determined by the regulatory bodies. ${ }^{49}$ Further they specify that 'there is no prescribed assessment method for assessing QLDs'. ${ }^{50}$ However, both the Bar Standards Board (BSB) and the Solicitors Regulation Authority (SRA) do specify a pass mark for foundation subjects on a QLD, currently set at $40 \% .{ }^{51}$ Consequently this may have implications for the choice of assessment made by lecturers; if a method (such as $\mathrm{OBE}$ ) is deemed to be innovative it can also be viewed as risky in terms of ensuring the majority of students pass at the required mark. Consequently it is seen as a form of assessment to be avoided.

Further, 'In January 2011, the Solicitors Regulation Authority, the Bar Standards Board and ILEX Professional Standards announced the establishment of a joint fundamental Review of the legal education and training requirements of individuals and entities delivering legal

\footnotetext{
${ }^{49}$ Bar Standards Board and the Solicitors Regulation Authority, 'Bar Standards Board and Solicitors Regulation Authority, Academic Stage Handbook (version 1:4)’, BSB and SRA, July 2014, s.2a, p.4.

${ }^{50}$ Ibid, s.4a, p.4.

${ }^{51}$ Ibid, Appendix 3, s.1.10; Appendix 4, s.1.7.
} 
services. ${ }^{52}$ One of the noted objectives was to 'enhance consistency of education and training through a more robust system of learning outcomes and standards, and increased standardisation of assessment' ${ }^{53}$ Specifically noting CBE and OBE, the Legal Education and Training Review (LETR) report acknowledges that, '[...]. Differences in assessment methods (e.g. between open-book and closed-book assessment) may also result in a marked difference in pass rates between different institutions and weaken the 'face validity' of the assessment process as a whole'. ${ }^{54}$ However this is presented not as an argument against OBE but rather to ensure awareness among stakeholders of the impact of varying examinations and assessment methods. It may however be symbolic of the 'risk factor' acknowledged previously of undertaking innovative assessment. ${ }^{55}$

Another significant recommendation within the LETR report was that

'[...] there should be a discrete terminal assessment of legal writing and critical thinking skills, ${ }^{56}$ [...]. Academic stage providers should retain discretion in setting the context and parameters of the task, provided that it is sufficiently substantial to give students a reasonable but challenging opportunity to demonstrate their competence., ${ }^{57}$

\footnotetext{
${ }^{52}$ LETR, 'Setting Standards - The Future Of Legal Services Education And Training Regulation In England And Wales: The final report of the Legal Education and Training Review independent research team', June 2013, p.v.

${ }^{53}$ LETR, 2013, p.xv.

${ }^{54}$ LETR, 2013, Sect.4.129, p.148. Original footnote 63, p.148: "”Face validity” is used to describe the most basic and common standard of validity applied to educational assessments (among other things). It is a qualitative standard that reflects the social expectations of the key stakeholders in a test, eg, the setter, moderator and subject. The closer the views or expectations of these persons are aligned with regard to the appropriateness of the assessment, and the fairness and accuracy of its results, the better its face validity.

${ }^{55}$ See previous discussion above regarding pass marks for Foundation subjects.

${ }^{56}$ Emphasis added.

${ }^{57}$ LETR, 2013, p.151. See also Recommendation 11, p.xv.
} 
It is interesting to note that these professional legal bodies recognise the importance of critical thinking skills. Moreover they also identify the importance of curriculum alignment when designing assessment:

'Effective instructional design needs close alignment between outcomes, learning approaches and assessment. Assessment in particular serves to demonstrate that student or trainee learning outcomes have been achieved. Assessment judgments provide the primary means of ensuring competence to progress to the next stage of training, or achievement of the standard expected of a newly qualified lawyer, and hence perform an important public protection function. However there are risks that over-prescription in setting assessment methods, and teaching and learning processes can stifle innovation, and limit opportunities for quality enhancement. ${ }^{58}$

\section{Purpose of a Law Degree}

The view taken in the review is indeed promising and challenges the myth often perpetuated in Law Schools that CBE and orthodox methods of assessment are required in order to satisfy the professional requirements of a QLD. If this is the case the question must be asked as to why this falsehood continues? One could argue that is due to a more fundamental underlying issue of what the purpose and function of a law degree should be. During the review of legal education the LETR found that the QLD served 'multiple purposes and should not be

overregulated.' 59 As one solicitor respondent to the online survey observed, 'There must be

\footnotetext{
${ }^{58}$ LETR, 2013, Sect.4.122, p.147.

${ }^{59}$ LETR, 2013, p.xiv.
} 
scope for law as a liberal art, as well as a career, and a balance must be struck' ${ }^{60}$ This is important as many law students for varying reasons do not pursue a career in law once they have graduated from university. ${ }^{61}$ It is also the case that there are many students who undertake law degrees who do not want to practice law as a profession but undertake a law degree because they view it as a rigorous academic qualification. It is submitted that the ability to learn and utilise higher cognitive skills is a generic learning outcome valuable to all disciplines. As such these teaching learning and assessment of such skills has educational and employment value for all students including law students.

It is also the case that higher education institutions and law departments will have their own academic, institutional and departmental objectives for their law degrees. ${ }^{62}$ Perhaps then we should look inwards rather than to external bodies in order to understand why the discipline of law has been so reluctant to progress from traditional assessment forms and CBE in particular. What is certainly true is that due to the particular historical development of law as a discipline the role of recall and memorisation has a particular prevalence and importance within legal education. ${ }^{63}$ As such, the CBE has tended to be the form of examination prevalent in law. The hegemonic European legal education tradition 'has involved students committing to memory large tracts of substantive law in order to demonstrate mastery over it... Students subsume law, become it, enter into the profession. ${ }^{64}$ Whilst the importance of memorisation is not doubted particularly for those wishing to practice law, it is only one of many skills students require in order to be effective practitioners of law. Indeed in terms of

\footnotetext{
${ }^{60}$ LETR, 2013, Sect.2.49, p.26.

${ }^{61}$ It is important to acknowledge that the traditional professions are now a minority career destination for law graduates. See LETR, 2013, Sect. 4.105, 144.

${ }^{62}$ Ibid.

${ }^{63}$ Maharg.P, 1999, p.222.

${ }^{64}$ Ibid., p.227.
} 
preparing students for legal practice, Donnelly notes that solicitors and barristers never rely on memory alone - rather they resolve legal problems through analysing and 'synthesising information under time constraints. ${ }^{65}$ Thus as practicing lawyers commonly consult legal sources when undertaking legal cases, 'Open-book exams, [...], are probably more authentic than closed-book exams. ${ }^{66}$

As such, it is submitted that other skills such as critical thinking and synthesis and application of knowledge are equally if not more important that memorisation. Recall and 'rote learning can be a passive, inert rehearsal of information, which encourages docility in students, ${ }^{67}$ rather than encouraging the 'lawyerly skills' anticipated (such as expressing themselves cogently, synthesising strings of arguments and manipulating knowledge at will). ${ }^{68}$ Therefore, as Maharg states, although one can appreciate why memory and oral assessment (oral skills) dominated legal education in the past, particularly in pre-print cultures, the nature of legal practice has changed dramatically over the last century. As such he argues 'forms of teaching and assessment ought to adapt to accommodate this. ${ }^{69}$

\section{Student Views - Empirical Study and findings}

In response to the lack of literature concerning $\mathrm{OBE}$ and Law students in particular, the author conducted a small-scale empirical pilot study in order to ascertain student views

\footnotetext{
${ }^{65}$ Donnelly.L, 2005, p.106.

${ }^{66}$ Azin, 2004, p.781.

${ }^{67}$ Maharg.P, 1999, p.222.

${ }^{68}$ Ibid., p.224.

${ }^{69}$ Ibid.
} 
regarding the wider question of assessment in law including the use of OBE and CBE. ${ }^{70} \mathrm{~A}$ questionnaire was distributed to 150 second year students at the end of two 10 week modules. These modules are currently assessed by 50\% coursework and 50\% CBE. No explanation of assessment types or discussion of assessment took place prior to this questionnaire due to time constraints, so the students understanding of what an open-book exam consists of is not confirmed. Neither did the study ask students to prioritise $100 \%$ OBE or CBE or coursework. ${ }^{71}$ Rather the questions asked were open-ended, asking for opinions on types of assessment. 47 students responded. Students were asked 'What kinds of assessment do you prefer and why?' 11 responded that they liked traditional examinations (CBE) several citing that they 'liked working under pressure'. 10 students noted they would prefer open-book or seen exams. ${ }^{72}$ Reasons stated for this included 'OBE allow me to prepare more thoroughly' indicating some awareness of a link between this type of examination and depth of knowledge and '[OBE] allow me to focus on remembering important information, rather than focusing on memorising legal articles and subsections. ${ }^{73}$

2 students noted a preference for coursework only stating that essays allowed 'more critical analysis and more time to explore ideas'. This raises an important question as to the rationale for having OBE rather than several pieces of coursework: In OBE students would similarly have time to 'explore ideas' but in addition there is still an element of pressure, as the student has to answer an unseen question (questions), written in timed exam conditions. The student can show that they can work to deadlines and under pressure. Furthermore, study skills can

\footnotetext{
${ }^{70}$ This could be used as a pilot study for a more extensive empirical project.

${ }^{71}$ A further more extensive study could ask such a question and gain more in depth views of the understanding of OBE and views regarding priorities and weighting of types of assessment. Further disaggregated data could be obtained on gender of participants and year of study.

${ }^{72}$ Students did not differentiate between seen and open-book exams but this could be due to the question being very general and not specifically differentiating between these types of examinations.

${ }^{73}$ Primary data gathered Lancaster University Law School, June 2013, on file with author.
} 
be assessed, such as the student's ability to find and select appropriate information, analyse sources and apply to a particular context.

What is interesting is that from across the whole sample of students including those who preferred CBE and OBE, 18 advocated the use of problem based questions. Reasons cited include 'apply knowledge and skills'; 'aid in my application of law and therefore develop my understanding'; allow me to give 'more detail' and 'more useful for practice of law - to see how it applies'. Whilst problem-solving questions can be incorporated into both CBE and OBE it can be argued that the later allows for deeper and detailed responses and critical analysis of the problem. Thus students seemed to be aware that the uses of higher order cognitive skills were preferable and required for deeper learning. Furthermore, it is suggested that students were also aware that the type of questions asked were significant rather than the type of examination itself.

\section{Multi-method Approach}

The author is not advocating $100 \%$ OBE or indeed $100 \%$ weighting for any one type of assessment. As stated the students who took part in the pilot study had experienced a course based upon 50\% coursework and 50\% CBE. Although the author utilised a variety of assessment tasks throughout the course that was piloted for the study (for example, oral presentations; posters; jigsaw reading exercises) these were formative assessment tasks rather than summative. The arguments regarding the merits of formative versus summative assessment are outside the scope of this article. However, the impact of this decision is another factor to be considered when designing the curriculum and preparing students for an 
OBE. As such, the author would advocate a multi-method approach to assessment that is critically aligned with the curriculum of the course and the learning outcomes. ${ }^{74}$ As Aizen argues the validity, reliability and pedagological utility of law school assessments can be improved through increasing the variety and quality of assessment methods. ${ }^{75}$ Although Aizen was writing in the context of the USA postgraduate legal educational system his observations are also common to academic legal education in England and Wales. The argument is not that additional assessment is necessarily required (although in some cases more formative assessment would need to be incorporated into the curriculum for example to prepare students for OBE or problem-solving questions), rather, that a variety of assessments will be beneficial for the students in terms of exhibiting their competencies, preparing them for a career as a lawyer or indeed outside of law and for supporting varying learning styles. According to the BSB and SRA statement on the skills to be acquired on a QLD, these would include 'Legal research, analysis and application "to the solution of legal problems”, oral and written communication "to the needs of a variety of audiences", general transferable skills including problem solving, use of language "with care and accuracy”, electronic research, communication and word-processing. ${ }^{76}$ As such a variety of methods are required to assess competency in these skills, for example, skills such as interviewing, mooting and negotiating $^{77}$ cannot be assessed through traditional CBE or OBE.

\footnotetext{
${ }^{74}$ Biggs. J, Teaching For Quality Learning at University, Oxford: OUP, 1999.

${ }^{75}$ Aizen.R, 'Four Ways to Better 1L Assessments', Duke Law Journal, Vol.54, 2004, pp.765-794, at p.779.

${ }^{76}$ Bar Standards Board and Solicitors Regulation Authority, July 2014, Appendix 1, Schedule 1a and b. See also LETR, 2013, Annex I, p.67.
}

${ }^{77}$ Aizen.R, 2004, p.780. 


\section{Conclusion}

Having reviewed the arguments for and against the use of OBE and in particular considered their application in teaching and learning in the Law School, it is suggested that whether examinations are OBE or CBE a key issue is good curriculum design with clearly aligned learning outcomes throughout the teaching and learning activities and the assessment tasks. It is also argued that a variety of assessment methods allows students with varying learning styles to achieve their potential utilising a range of knowledge and skills. It is therefore, crucial that we as teachers/lecturers understand ourselves what we are hoping to achieve in our courses and the need to adjust our own teaching \& learning styles and methods to account for changes in assessment. Assessment should be integral to curriculum design and if changes to the methods of assessment are made at a later stage the course should be altered accordingly. It is not clear whether OBE are always preferential to CBE. Rather it will depend upon what we want the students to achieve. ${ }^{78}$ If preference is to be given to achieving higher cognitive skills rather than recall and memorisation then these skills need to be incorporated within the learning outcomes of the course, as well as through the assessment. Moreover these learning outcomes need to be communicated to the students and aligned with the teaching methods used.

Law schools in particular need to think about how they can diversify assessment - not only to make it more interesting for students but to make it more purposeful rather than purely focused on reciting facts. This of course will be influenced by our ideas of what a legal education should entail and of what the purpose of a Law degree should be (whether for

\footnotetext{
${ }^{78}$ Hinnet.K and Bone. A, 'Diversifying Assessment and Developing Judgement in Legal Education' in Burridge. R, Hinett. K, Paliwala.A and Varnava.T, Effective Learning and Teaching in Law (ILT Effective Teaching \& Learning), Oxford: Routledge, 2002, pp.52-80 at p.55.
} 
professional practice preparation only or as an academic exercise in its own light or a mixture of both). As Hinnet and Bone note, 'Diversification of assessment is [therefore] central to the achievement of a coherent and challenging law curriculum'. ${ }^{79}$ Moreover in light of recent research on the global law curriculum as oppose to inward looking English versions of a law curriculum $^{80}$ there is a need to rethink the whole remit of legal education and its aims, skills and knowledge base, including reviewing priorities for assessment.

It is evident that the ' $\mathrm{OB}[\mathrm{E}]$ has considerable potential for changing and improving the traditions of assessment and the learning environment in general' ${ }^{81}$ However in order to be successful in these aims the introduction of OBE must be accompanied by a holistic review of the teaching and learning within Law schools. ${ }^{82}$ OBE can challenge the orthodoxy of assessment to be found within the discipline of law. More importantly if considered as an element of wider curriculum design at module and programme level OBE can contribute to improving teaching and learning in Law.

\section{5,756 words including footnotes}

\footnotetext{
${ }^{79}$ Hinnet.K and Bone. A, 2002, pp.52-80 at p.55.

${ }^{80}$ Smits.J, 'European legal education, or: how to prepare students for global citizenship?' The Law Teacher, 45:2, 2011, pp.163-180.

${ }^{81}$ Eilertsen.T.V and Valdermo.O, 2000, p.102.

${ }^{82}$ As of January 2015, in a wider review of current practice within the Law School the author found that no OBE are in use at undergraduate level.
} 